\title{
TERRITÓRIO, CLASSE SOCIAL E SUJEITOS: DESAFIOS TEÓRICOS CONTEMPORÂNEOS ${ }^{1}$
}

\author{
Ana Cristina da Silva ${ }^{2}$
}

\begin{abstract}
Resumo: $O$ presente artigo tem por objetivo por em questão a relação entre território, classe social e sujeitos no sentido de elucidar tal relação, que se manifesta como um dos desafios teóricos contemporâneos. Em sua origem recente, trata-se de um texto de intervenção no $\mathrm{V}$ Circuito da Sociobiodiversidade. Todavia, no pensamento geográfico brasileiro, as pesquisas sobre território se intensificaram a partir da década de 1980 e perduram até as primeiras décadas do século XXI, tal como se pode verificar nas investigações de Silva $(2010,2013,2016)$. Conceito basilar da ciência geográfica, o território tem sido pensado em suas relações com a técnica, a cultura, a cidadania e a política, a economia e o desenvolvimento. Nossa abordagem se deteve nos vínculos entre território, classe social e sujeitos sociais no âmbito da "geografia crítica", com destaque para as duas últimas décadas do século $\mathrm{XX}$ até o momento atual.
\end{abstract}

Palavras-chave: Território; Classe Social; Sujeitos.

\section{TERRITORY, SOCIAL CLASS AND SUBJECTS: CONTEMPORARY THEORY CHALLENGES}

\begin{abstract}
This article aims to question the relations between territory, social class, and subjects, elucidating this relation expressed as one of the contemporary theoretical challenges. In its recent origin, it is an intervention text in the 5th Social and Biodiversity Circuit. However, in the Brazilian Geographical Thought, the researches about territory intensified from the 1980s and lasted until the first decades of the 21st century, as it is possible to verify by the investigations of Silva (2010, $2013,2016)$. As basis concept of the geographical science, the territory has been thought in its relations with technique, culture, citizenship, politics, economy, and development. This approach links territory, social class, social subjects in the scope of the "critical geography", with highlights for the two last decades of the 20th century so far.
\end{abstract}

Keywords: Territory; Social class; Subjects.

\footnotetext{
1 Texto originalmente produzido para intervenção na Mesa Redonda, com o mesmo título, no V Circuito da Sociobiodiversidade, realizado na Cidade de Goiás, em fevereiro de 2019.

${ }^{2}$ Doutora em Geografia pela Universidade Estadual Paulista: Júlio de Mesquita Filho, em Presidente Prudente. Professora no Curso de Graduação em Geografia e no Programa de Pós-Graduação em Geografia, no Instituto de Estudos Socioambientais (IESA), da Universidade Federal de Goiás (UFG), Regional Goiânia. ana.iesa.ufg@ gmail.com.
}

Estudos Geográficos, Rio Claro, 17: 4-26, jan./jun. 2019 (ISSN 1678-698X) http://www.periodicos.rc.biblioteca.unesp.br/index.php/estgeo 


\section{INTRODUÇÃO}

Embora se possa afirmar que o território é um conceito basilar da ciência geográfica e que atualmente tem sido também objeto de estudos nas ciências sociais, os desafios em elucidá-lo não são menores, apesar da vasta produção bibliográfica existente. No que se refere ao pensamento geográfico, há a exigência de uma tomada de posição perante o pensamento herdado quanto ao território, em sua relação com o estado e a política, posto que o século XIX é emblemático dessa relação.

No entanto, no século XX, a atuação das classes sociais e dos sujeitos sociais impuseram questões essenciais, particularmente, à Geografia, a saber: qual é a dimensão espacial e político-territorial das classes e dos sujeitos sociais? Em que medida o território importa, condiciona e é condição de reprodução das classes e dos sujeitos? Não há respostas consensuais para estas questões. Mas há a percepção de que os conflitos sociais têm uma dimensão territorial onde quer que ocorram e nas diferentes escalas: local, regional, nacional e global. Essas questões evidenciam de que forma esse tema nos afeta e demonstram as preocupações de ordem ontológica e epistemológica na Geografia contemporânea.

Nosso marco temporal tem por referência o pensamento geográfico brasileiro contemporâneo, sobretudo, aquele formulado a partir do Movimento de Renovação da Geografia, desde as décadas finais do século XX, até as duas primeiras décadas do século XXI. Nossos pressupostos são os de que há uma dimensão político-territorial das classes e dos sujeitos sociais e de que o território é uma condição de possibilidade de coesão social. Esses dois pressupostos são norteadores de nossa abordagem. Todavia, foi necessário identificar, no curso do Movimento, como os "sujeitos" foram se constituindo como objeto de análise na polissemia das abordagens.

\section{O MOVIMENTO DE RENOVAÇÃO E SUAS PAUTAS}

A década de 1970 tornou-se um marco do Movimento de Renovação da Geografia em nível mundial e nacional ${ }^{3}$. Em ambos os níveis, as pautas convergiam em torno das noções de crise e de crítica à Geografia vigente. Embora o Movimento não tivesse um projeto ou programa previamente definido, com lideranças préestabelecidas, isso não significa que não houvesse protagonistas e pautas a serem debatidas. As pautas foram se delineando à medida que avançava o Movimento. Havia uma percepção de que a crise da Geografia se devia: ao predomínio do empirismo em detrimento da teorização; à ausência de conceitos e categorias próprios, muitas vezes tomados de empréstimos às ciências sociais; à indefinição do objeto de estudo, mesmo quando se afirmava ser a relação homem-meio ou espaço a demarcação em relação a outras ciências (naturais ou humanas) persistia, uma vez que várias delas também estudam a relação homem-meio ou a sociedade em relação ao espaço. Ainda mais ambígua se tornava a Geografia diante da "virada espacial" nas ciências sociais, posto que a defesa do espaço como objeto de estudo dos geógrafos implicava em apresentar as especificidades metodológicas com as quais abordavam tal objeto ${ }^{4}$. Não era suficiente advogar o espaço como objeto de

\footnotetext{
${ }^{3}$ Ressalta-se que o Movimento de Renovação não tinha um conteúdo programático previamente estabelecido, tampouco um consenso quanto aos caminhos a seguir.

${ }^{4}$ Para uma compreensão da "virada espacial" na Geografia ver Claval (2002).

Estudos Geográficos, Rio Claro, 17: 4-26, jan./jun. $2019 \quad$ (ISSN 1678 -698X)

http://www.periodicos.rc.biblioteca.unesp.br/index.php/estgeo
} 
estudo da Geografia, tampouco adjetivá-lo de geográfico, era necessário precisar como, o método, para conhecê-lo ${ }^{5}$. Essa exigência epistemológica se impôs ao pensamento geográfico naquelas décadas finais do século $X X$ e a crise foi exaltada na sua positividade como abertura ao novo, ressaltou Gonçalves (1978). Porém, nem todos os geógrafos perceberam a crise do mesmo modo.

A crítica como atitude e método também direcionou o Movimento de Renovação. Vinculada à crise epistemológica, a crítica ideológica pautou os discursos da Renovação. A crítica converteu-se num adjetivo que qualificava essa "geografia nova" ou "geografia crítica" que estava sendo fundada 6 . A crítica, como categoria basilar do método, foi "aplicada" ao pensamento geográfico, sem a qual não se podia revisar a história da Geografia. Inauguravam-se outras formas de narrativa e de "historiografia" da Geografia, no sentido de depurá-la da ideologia. No entanto, mesmo como método, a crítica havia se mostrado ineficiente ao corte e à ruptura epistemológica pretendida, quando, segundo Milton Santos (1996a), a crítica precedeu ou abandonou a análise. A crítica também se converteu num slogan a atrair adeptos e promover a mobilização, como demonstra Silva (2011). Nesse sentido, ser crítico era assumir uma atitude de negação perante o pensamento herdado, era "tomar partido" e assumir uma posição revolucionária, de "esquerda" ou progressista, jamais conservadora diante da realidade social e política" ${ }^{7}$.

A busca por fundamentos distintos e novos, que não aqueles da Geografia clássica ou da Nova Geografia, foi outra pauta da Renovação. Um desses fundamentos foi encontrado no materialismo histórico e dialético ${ }^{8}$, no qual se acreditava encontrar: os aportes de uma crítica, simultaneamente, epistemológica e ideológica; a superação das dicotomias entre sociedade e natureza e, por conseguinte, da dualidade entre Geografia Física e Geografia Humana; uma perspectiva dialética a balizar um projeto unitário e a visão de totalidade. A adoção de um vocabulário marxista, conceitos e categorias, evidencia o impacto que o marxismo teve no Movimento de Renovação, como demonstra um estudo feito por Silva (1984), cobrindo um período de sete anos, de 1976 a 1983, sobre a produção geográfica brasileira. Nesse estudo, foi realizado um levantamento criterioso, a produção foi avaliada sob a forma de resenhas e identificou-se, além do predomínio da categoria espaço, a terminologia marxista.

As categorias mais utilizadas pelos geógrafos críticos e radicais em sua linguagem (até cinco ocorrências) - [...] - são as seguintes: sociedade, classes sociais, homem, forças produtivas, trabalho,

\footnotetext{
${ }^{5}$ Desse período, há que se destacar algumas das obras de Milton Santos (1978, 1980, 1985, 1988a, 1988b)) e o seu papel em assumir essa exigência e transformá-la num projeto epistemológico destinado a demarcar e legitimar a Geografia perante as demais ciências.

${ }^{6}$ Parte significativa das publicações desse período, final da década de 1970 e da década de 1980, trazem a insígnia da crítica, tais como: Por uma geografia nova: Da crítica da Geografia a uma Geografia Crítica (1978), de Milton Santos; Geografia: pequena história crítica (1a edição é de 1981) e a dissertação: Contribuição para uma história crítica do pensamento geográfico: Alexandre Von Humboldt, Karl Ritter e Friedrich Ratzel (1983), de Antônio Carlos Robert Moraes; Geografia crítica: a valorização do espaço (1983), de Antônio Carlos Robert Moraes e Wanderley Messias da Costa; $O$ que é Geografia? (1980) e $O$ discurso do avesso: para a crítica da geografia que se ensina (1987), de Ruy Moreira, para citar apenas algumas de maior circulação.

${ }^{7}$ Para um balizamento das concepções de crítica e de radical no pensamento filosófico e na Geografia ver Vesentini (2009).

${ }^{8}$ Segundo Geiger (2001, p. 120) houve uma breve aproximação entre a Geografia e o marxismo, no Brasil, nas décadas 194050, mas foi insuficiente para deflagrar um movimento de renovação tal como o da década de 1970. Assim, ele relata esse momento: "na época, não havia marxistas para serem citados na Geografia. [...]. Mas o fato era que o marxismo estava fora da Geografia. E naquela época, eu me lembro, havia dúvidas no marxismo quanto a Geografia Humana como ciência. [...]. Quanto a Geografia Humana, seria uma parte da Economia Política”. Mas também, há que se reconhecer, com Freitas (2014), que o materialismo histórico e dialético não foi a única tendência filosófica no Movimento de Renovação da Geografia, no Brasil. Ainda que tenha se tornado a referência predominante na geografia crítica e radical.
}

Estudos Geográficos, Rio Claro, 17: 4-26, jan./jun. 2019 (ISSN 1678-698X) http://www.periodicos.rc.biblioteca.unesp.br/index.php/estgeo 
prática, urbanização, práxis, valor, valor do espaço, forma, processo, relação, determinação, movimento, objeto, teoria, ideologia, linguagem, método, real, totalidade, natureza, espaço, espaço geográfico, arranjo espacial, paisagem, forma espacial, lugar, formação econômico-social, modo de produção, capitalismo, produção, formação social, mercadoria, país subdesenvolvido, função, capital e Estado-Nação. (SILVA, 1984, p. 132)

Entretanto, importava saber as condições de possibilidade e os limites do materialismo histórico e dialético no estudo do espaço, pois a adesão ao marxismo não se deu sem considerações e críticas ${ }^{9}$. Além de suprir a exigência de uma formulação rigorosa de seu objeto, uma das pautas da Renovação, vinculou-se às demandas por transformação social, nas quais a práxis era premente e impunha mudanças na concepção da funcionalidade estratégica do saber geográfico, outra pauta legítima do Movimento. À Geografia caberia não só "desvendar as máscaras sociais", como denunciava Moreira (1982), como também promover a transformação social e política. O espaço como produto e condição de reprodução da sociedade, premido pela luta de classes, pela contradição entre trabalho e capital, impunha que se considerasse que qualquer revolução social passava, necessariamente, por uma "revolução" na relação entre a sociedade e seu espaço.

\section{ESPAÇO OU TERRITÓRIO: TENSÕES EM TORNO DO OBJETO}

O espaço, como objeto de estudo, possibilitava manter a concepção clássica da relação homem-meio ou sociedade-natureza, mas doravante essa relação devia ser pensada pela mediação do trabalho ${ }^{10}$. Como produto e condição de reprodução da sociedade, campo de luta das classes sociais e das relações de poder, o espaço era a evidência da contradição fundamental entre capital e trabalho que constitui o capitalismo. Identificam-se no trabalho tanto a atividade autoprodutora do homem como também seu reverso: a alienação. Procurava-se um estatuto ontológico e epistemológico para o espaço geográfico. Durante a década de 1980, a produção teórica visava dar conta desse estatuto, como se pode conferir em Santos (1988), no texto: O espaço geográfico como categoria filosófica. Nele se definem a Geografia e o papel que nela desempenham as técnicas, como também a teoria e o método para o estudo do espaço.

O espaço resultado da produção, e cuja evolução é consequência das transformações do processo produtivo em seus aspectos materiais ou imateriais, é a expressão mais liberal e também mais

\footnotetext{
${ }^{9}$ Essas considerações e críticas se manifestaram em nível internacional, como na França, com Lacoste (1989), e no Brasil, esse balizamento pode ser constatado no livro: Novos rumos da geografia brasileira, organizado por Milton Santos (1996c), particularmente em seu artigo: Alguns problemas atuais da contribuição marxista à geografia. É preciso ressaltar o marxismo, na Geografia brasileira, no período do regime militar não era comum e uma das formas de contato com autores marxistas se dava por meio de grupos de estudo e seminários, como relata Arantes (2000, p. 343): “Com a vida política bloqueada pela ditadura, a vida cultural de oposição foi se recompondo a conta-gotas, primeiro na forma de grupos de seminários mais ou menos privados e discretíssimos - de profissionais liberais à procura de cultura geral, a universitários interessados em se atualizar, e a boa nova naquele momento era o circo francês das ciências humanas -, depois em conferências públicas isoladas, até desaguar nos grandes comícios da SBPC [Sociedade Brasileira para o Progresso da Ciência]".

${ }^{10}$ Diferentemente da concepção marxista, encontra-se o tema do trabalho em Ratzel, segundo Carvalho (1998), e o da técnica, vinculado aos "gêneros de vida", em La Blache (1928).

Estudos Geográficos, Rio Claro, 17: 4-26, jan./jun. $2019 \quad$ (ISSN 1678-698X)
} http://www.periodicos.rc.biblioteca.unesp.br/index.php/estgeo 
extensa dessa práxis humana, sem cuja ajuda a existência não pode ser entendida. Assim, o pensamento espacial não se pode fazer fora da busca de uma compreensão do fato tal qual se dá, mas uma busca que vai além da apresentação e nos permite chegar à representação. (SANTOS, 1988a, p. 12)

Havia a necessidade de se avançar na teorização e na proposição de um método que desse conta da complexidade do espaço geográfico na sua totalidade.

As noções de estrutura, processo, função e forma, essas velhas categorias filosóficas e velhas categorias analíticas devem ser retrabalhadas para que, neste particular, possam prestar serviços à compreensão do espaço humano e à constituição adequada de sua respectiva ciência. Ademais, esses instrumentos nos permitem tomar como ponto de partida o concreto das coisas, sem nos deixar todavia ofuscar pelos nossos sentidos. Da forma à estrutura e desta, de novo, à forma, temos o caminho que conduz a uma fenomenologia do espaço e à sua construção teórica. A forma nos apresenta a coisa, o objeto geográfico; sua função atual nos leva ao processo que lhe deu origem; e este, o processo, nos conduz à totalidade social, a estrutura social que desencadeou e dá ao objeto uma vida social. (SANTOS, 1988, p. 13).

Todavia, as proposições teóricas e metodológicas de Santos não eram consensuais nessa geografia que se estava a fundar. Tampouco havia consenso sobre a geografia crítica e a hegemonia que o espaço nela ocupava como objeto de estudo. A ausência de consenso se apresentava nas críticas endereçadas à geografia crítica pela sua incapacidade de ser propositiva em termos de um projeto nacional, quando o Brasil se libertava de mais de duas décadas de regime militar e tentava recuperar a democracia.

Fundada na imanência do capital e de seu espaço, a chamada "Geografia Crítica" tem apenas se restringido em procurar interpretar o mundo a partir do conflito básico entre capital e trabalho; reduzindo ao esquecimento a luta política e econômica que a propriedade do capital e da terra cria no interior da classe dominante. Desse modo, inexiste o conflito nacional ou regional já que o interesse dos capitalistas seria homogêneo em toda a superfície da terra, ou pelo menos naquela porção onde o socialismo não é o modo de produção dominante. (EGLER, 1983, p. 73)

A crítica de Egler, à geografia crítica, tocava também numa questão polêmica no interior do marxismo, a saber, a questão nacional e como conciliá-la com o "internacionalismo proletário". Embora a crítica enfatizasse a necessidade de um projeto nacional para o Brasil, ela se desdobrava e afetava a compreensão dos geógrafos brasileiros acerca da questão nacional e das transformações ocorridas nas décadas finais do século XX.

A "Geografia Nova" tem sido incapaz de analisar e compreender as profundas transformações que se processaram nos últimos trinta anos no quadro político-territorial do mundo contemporâneo, quando as grandes empresas, embora possuam estratégias espaciais a nível internacional, expressa na materialização dos investimentos uma

Estudos Geográficos, Rio Claro, 17: 4-26, jan./jun. 2019 (ISSN 1678-698X) http://www.periodicos.rc.biblioteca.unesp.br/index.php/estgeo 
política territorial que garanta, através da propriedade efetiva de largas proporções do globo, a valorização dos capitais aplicados. (EGLER, 1983, p. 74)

Essas críticas de Egler (1983, p. 74) punham em questão o discurso da crise da Geografia e provocava a reflexão: "[...] as novas tendências do pensamento geográfico têm sistematicamente deixado de lado a análise da realidade concreta, territorialmente definida. [...] antes de uma crise da geografia, o que existe é uma crise dos geógrafos [...]". E sem abandonar as categorias de análise marxistas, Egler alertava os geógrafos a dar mais atenção à materialidade do espaço, situando o território no cerne do debate da teoria geográfica e do pensamento geográfico.

A materialidade do espaço se manifesta no território, que é sujeito à apropriação privada, à luta pela sua posse e de seus recursos naturais. É o uso e a apropriação do território que desnudam o caráter do capitalismo e trazem à tona as relações concretas de produção. Cenário ativo da luta de classes, da concorrência entre os detentores dos meios de produção, o território é a determinação concreta das contradições do modo capitalista de produção. (EGLER, 1983, p. 75, grifos nossos)

Todavia, essa tensão entre espaço e território evidenciava também um conflito entre a tradição e a renovação em curso na Geografia brasileira, pois: "ao se propor a analisar o espaço, enquanto categoria básica, [a Geografia nova] rompe com a tradição empirista da geografia tradicional" (EGLER, 1983, p. 75) e perde uma dimensão importante dessa geografia. A perda desse elemento da tradição desvalorizava a geografia nova, pois "ao perder de vista a dimensão territorial dos fenômenos espaciais, a geografia corre o risco de transformar-se em 'espaciologia', diluindo sua eficácia enquanto ciência e enquanto instrumento de análise e transformação da realidade" (EGLER, 1983, p. 75). Não se tratava de um elemento acessório, mas essencial à tradição porque se refere à identidade da ciência geográfica. Dito de outro modo, porque "A geografia nasceu como 'ciência do território', entendendo o território como a porção da superfície da Terra sujeita à apropriação pelas formações sócio-econômicas nos diferentes estágios de desenvolvimento" (EGLER, 1983, p. 75).

O momento histórico se impunha à reflexão e à tomada de decisão não apenas em relação à democracia, mas também em relação à economia e ao desenvolvimento do Brasil ${ }^{11}$. As perspectivas futuras, como vislumbrava Egler (1983, p.78), demandavam uma "política territorial do Estado" brasileiro e o posicionamento dos geógrafos. O desafio estava lançado. Aliado a esse desafio, no plano teórico e prático, persistia a questão de como conciliar nacionalismo e universalismo revolucionário.

Egler não era a única voz destoante a criticar a geografia renovada. Outra delas ampliou a crítica e denominou de "espaciologia" o que havia se tornado o primado do espaço na Geografia crítica. Para Souza (1988), o espaço social era uma categoria fundamental nas Ciências Humanas, bem como na Geografia Humana, mas não havia sido tão destacada como naquelas décadas finais do século XX. Sua valorização, sobretudo quanto ao uso que dela os geógrafos faziam, estava constituindo uma "corrente espaciológica".

\footnotetext{
${ }^{11}$ O país vivenciava um período de transição entre declínio do regime militar e a luta pela redemocratização.

Estudos Geográficos, Rio Claro, 17: 4-26, jan./jun. 2019 (ISSN 1678-698X) http://www.periodicos.rc.biblioteca.unesp.br/index.php/estgeo
} 
A "corrente" espaciológica, na verdade, consiste no alçamento a um plano epistemológico (fundação de uma nova ciência) da proposição de autonomia do Espaço perante as relações sociais, a qual é prenhe de equívocos, da parte dos espaciólogos e seus interlocutores, sobre a questão da natureza da totalidade social concreta onde se inscreve o Espaço. (SOUZA, 1988, p. 22, grifos do autor)

A crítica de Souza à "matriz lógica e ontológica do saber espaciológico", ou seja, ao primado do espaço como sujeito ou instância da sociedade, demonstrava que o discurso espaciológico deixava entrever a falta de fundamento epistemológico e ontológico. No entanto, Souza fez algumas ressalvas de modo a que não se pensasse haver um "bloco homogêneo" de espaciólogos e nesse sentido distinguiu algumas especificidades.

Milton centralmente interessado em, na esteira de um prestigiamento do Espaço, vendo-o como uma quarta instância da Sociedade (ao lado da econômica, da política-institucional e da cultural-ideológica), assegurar um lugar para a Geografia entre as ciências humana; Lefebvre, com uma posição mais sutil e complexa, [...], de sua parte mostra-se menos referenciado por horizontes disciplinares. (SOUZA, 1988, p. 23, grifos do autor)

Os contornos e o foco das objeções foram mais bem precisados por Souza (1988, p. 23): "A crítica que dirijo à Espaciologia é uma crítica de contexto. Não se trata de questionar indiscriminadamente a validade e a importância dos resultados que, sob o seu signo, têm sido obtidos no terreno da reflexão teórica sobre o papel do Espaço junto à dinâmica global da Sociedade [...]". Referenciado em Castoriadis (1922-1997), Souza identificava no discurso espaciológico a "lógica identitáriaconjuntista", posto que essa lógica conduzia a confundir espaço e sociedade ou de separá-los como dois entes autônomos. Essa autonomização impedia de se perceber a "dialética sócio-espacial" tal como ela era. Para Souza (1988, p. 26, grifos do autor): "A dialética sócio-espacial é, [...], somente um componente da dinâmica de todo o Social-concreto. Apartá-la de algum modo deste contexto, e é isso que sempre acontece ao se concebê-la segundo um projeto autonomizador, implica em esterilizá-la, formalizá-la".

A "lógica conjuntista-identitária", segundo Souza, fragmenta o todo social, desmembra espaço e sociedade e em seguida confere-lhes dinâmicas externas: ora como objetos, ora autonomizando o espaço como sujeito da sociedade. Nessa lógica conjuntista-identitária, a totalidade é fragmentada em compartimentos, as instâncias, o que resulta num formalismo que impede a compreensão da complexidade do social, e, por conseguinte, que ele "seja efetivamente concebido como um complexo inteiriço de agentes, movimentos, significações e 'materiais'" (SOUZA, 1988, p. 28). As objeções e críticas de Souza não isentaram nem mesmo autores como Edward Soja (1940-2015) e tampouco o marxismo como referencial da "espaciologia".

É lastimável ver espaciólogos e alguns de seus interlocutores, [...], insistirem para que se acrescente, à atual lista de instâncias ou correlatos, mais uma, a espacial, o que se legitimaria em função de sua "autonomia relativa" perante os processos sociais, expressa através da dialética sócio-espacial (é bem verdade que o próprio

Estudos Geográficos, Rio Claro, 17: 4-26, jan./jun. 2019 (ISSN 1678-698X) http://www.periodicos.rc.biblioteca.unesp.br/index.php/estgeo 
Edward Soja, em seu principal ensaio, rejeita a ideia da "estrutura separada", com leis próprias, mas, no final das contas, a sua percepção de uma "homologia dialética entre as estruturas espacial e social do modo de produção", com o sentido de que os conflitos estruturais e as lutas de classe são homólogos aos conflitos e desigualdades "espaciais", se faz por vias plenas de autonomizações ontológicas, na medida em que adota o marxismo como referencial). (SOUZA, 1988, p. 38)

Ao refutar a autonomia, ontológica, do espaço como uma instância da sociedade, Souza (1988, p. 39, grifos do autor) refutava também uma das correlações que se fazia, à época, entre o espaço e seus agentes, relativizando o papel do espaço "apenas como paciente da história (note-se bem, ainda que um paciente muito especial, cuja materialidade condiciona decisivamente os agentes)" nas Ciências Humanas e, portanto, na Geografia.

As concepções e tensões entre espaço e território, como objeto de estudo da Geografia, no debate epistemológico da geografia renovada não se restringia a Egler (1983) e Souza (1988) ${ }^{12}$. Oliveira (1999, p. 26-27) relatou como estabeleceu sua posição teórica e metodológica em relação ao Movimento de Renovação: "A teoria eu iria tomar de Marx, tudo aquilo que fosse suficiente para explicar o mundo, mas também não teria nenhum problema incorporar novas concepções teóricas, evidente que no campo do marxismo, pois tinha feito essa opção já no doutorado". Essa tomada de posição se fez acompanhar também de uma decisão quanto ao foco no espaço ou no território. A percepção do impasse epistemológico a que conduzia uma ontologia do espaço, nos termos propostos pela geografia crítica, parece ter se desdobrado numa compreensão da potencialidade do território para 0 pensamento geográfico. Com o texto Espaço e tempo: compreensão materialista e dialética, Oliveira (2000) demarcou sua posição em relação ao marxismo e sua ruptura com a tendência de privilegiar o espaço como objeto de estudo.

[...] já nesse momento [início da década de 1990] eu passo a trabalhar com a ruptura do ponto de vista do objeto. Eu abandono a ideia, embora [...] possa encontrar nos meus textos, o espaço, abandono a ideia de espaço e me coloco como projeto para construir, [...], elegi idealmente no começo o território, e vou investir na construção desse instrumental, de pensar esse objeto território que tinha uma implicação, primeiro de recuperar a geografia política e a geopolítica como produção científica da geografia, [...] e, como passo a admitir que a geografia era uma ciência social [...]. (OLIVEIRA, 2000, p. 43)

A opção pelo território, como categoria de análise, era fundamental à compreensão da acumulação capitalista e em relação às formas de reprodução da agricultura camponesa. Segundo Oliveira (2000), o capital age monopolizando territórios, num processo de territorialização do capital na agricultura que se diferencia da espacialização da luta pela terra no campo. Desse modo, territorialização do capital e espacialização da luta pela terra constituem dois conceitos necessários à compreensão do espaço agrário brasileiro.

\footnotetext{
${ }^{12}$ Com efeito, esse debate epistemológico no pensamento geográfico, no apogeu da renovação, não se limita a esses geógrafos. Mas seria impossível, nos limites desse artigo, referenciar todos aqueles que se pronunciaram criticamente a algumas das concepções mais vigorosas naquelas décadas de 1980 e 1990.

Estudos Geográficos, Rio Claro, 17: 4-26, jan./jun. $2019 \quad$ (ISSN 1678-698X)

http://www.periodicos.rc.biblioteca.unesp.br/index.php/estgeo
} 
No decorrer do Movimento de Renovação, o tema clássico da relação homem-natureza se interpôs entre a renovação e a tradição, e assim pode se plasmar com o espaço ou o território, simultaneamente. Há que se destacar Carlos Walter Porto Gonçalves, com um dos protagonistas da renovação da Geografia brasileira. Num momento em que as discussões e os debates giravam em torno do marxismo e do espaço na Geografia, Gonçalves se aproxima da "questão ambiental" e enfrenta as divergências entre geografia humana e geografia física e se posiciona: "Eu desde o início me envolvo com a questão ambiental, valorizo-a, coisa que eu acho que a esquerda recusa, tem dificuldade de tratar, trata de maneira secundária [...]". Relata Gonçalves (2000, p. 75). A militância política, a leitura de obras marxistas, a descoberta da luta de classes e da ideologia, a descoberta da "funcionalidade estratégica" da Geografia, se desdobraram em interesse pela questão da relação homem-natureza, declara Gonçalves (2000, p. 77): "Eu entro no debate dessa questão pelo lado dos trabalhadores percebendo como essa questão podia ser uma questão que ajudava no sentido da justiça social". A justiça social, a transformação social e a cidadania foram temas de debate no Movimento de Renovação. No entanto, o tema da cidadania parece ter tido uma configuração especial no pensamento de Milton Santos, tal como o interpreta Gonçalves (2000, p. 81-82): "[...] eu acho que o Milton levantou para a Geografia por que ele não era formado em Geografia. Esta questão da Geografia com a cidadania, essa Geografia com a questão do direito, ele é formado em direito". De acordo com Gonçalves, haveria uma relação intrínseca entre formação intelectual, pensamento geográfico e teoria geográfica ${ }^{13}$.

Os desdobramentos do marxismo na Geografia se apresentavam de várias formas, pois a preocupação com a cidadania ou a transformação e justiça social, implicavam uma reflexão sobre o papel do homem na sociedade e, por conseguinte, na Geografia renovada. Essa reflexão não encontrava respaldo teórico no "homem demográfico" dos estudos de população da geografia clássica. Com a introdução do marxismo na Geografia, a noção de classes sociais e de luta de classes exigia que se pensasse o homem como ser social a contrapelo do homem demográfico. Porém, nas várias vertentes do marxismo encontravam-se ênfases distintas, ora nas relações de produção, acentuando mais a dimensão política; ora nas forças produtivas, acentuando mais a dimensão econômica. Essas ênfases distintas desdobraram-se em perspectivas diferentes no que se refere ao espaço e ao território.

Talvez tenha que raciocinar assim, pode ser que alguma vertente da Geografia vá valorizar muito mais a questão das forças produtivas. Mas também, você vai entender um pouco minha origem no Trotsky, nos trotskistas que vão pegar a questão da política, então [...], é como se você tivesse dois marxistas, o marxismo das forças produtivas, mais economistas, o marxismo das relações de produção. E acho que vai dar duas Geografias distintas, uma Geografia que vai privilegiar o espaço como categoria da Geografia, que vai pegar, não é a toa que o Milton vai ser o principal protagonista dessa tendência, que vai privilegiar a questão da técnica como uma questão central, e o marxismo das relações de produção, que vai privilegiar a categoria território. Acho que esta é a grande distinção. (GONÇALVES, 1999, p. 84)

\footnotetext{
${ }^{13}$ Ver: O espaço do cidadão (1. ed. 1987), A formação do geógrafo no terceiro mundo (1. ed. 1978).

Estudos Geográficos, Rio Claro, 17: 4-26, jan./jun. 2019 (ISSN 1678-698X) http://www.periodicos.rc.biblioteca.unesp.br/index.php/estgeo
} 
Concordemos ou não com Gonçalves, o certo é que as discussões, em torno do objeto de estudo da Geografia renovada, se fizeram acompanhar de tensões e deslocamentos entre espaço e território. Até aqui pudemos pontuar algumas dessas tensões. Não poderemos mapear todas as motivações em torno dessas tensões e desses deslocamentos, mas podemos identificar as percepções e as motivações de alguns dos protagonistas do Movimento, por meio de seus relatos e suas publicações.

Por fim, cabe destacar outros dos protagonistas da renovação e o deslocamento que operam em torno entre espaço e território. Costa e Moraes (19542015) protagonizaram, a seu modo, a renovação e tinham, inicialmente, um projeto intelectual em comum ${ }^{14}$. Vejamos, portanto, a trajetória desses dois geógrafos em relação ao "encontro" com o território.

O geógrafo sempre é um apaixonado muito grande, pelo seu lugar e pelo olhar que ele desenvolve sobre as diferentes escalas. E, nesse ponto, para concluir essa primeira aproximação, vem daí, também, a minha tendência de valorizar o território mesmo. Porque o território é uma forma de você humanizar a região. O território nada mais é que a humanização da região, do lugar e do espaço. O espaço é uma categoria analítica, uma categoria válida para você tentar refinar os encadeamentos que você tem em mente [...]. (COSTA, 2010, p. 7, grifos nossos)

Nesse relato a Silva (2010), Costa destaca sua formação intelectual e pessoal e sua relação afetiva com a Geografia. Porém, a geografia teorética e a geografia crítica haviam saturado os conceitos de região e de espaço, mas o território os reabilitava e validava em outra configuração, o que teria motivado sua predileção pela Geografia Política: "Eu posso dizer que eu fui um dos brasileiros, geógrafos brasileiros, que redescobriu a Geografia Política. [...]. Tinha esse olhar para a política nacional, eu tinha esse olhar com a nossa história, com o nosso futuro [...] de fazer alguma coisa pelo país [...]". (COSTA, 2010, p. 30). Havia outra motivação que animava o interesse pela Geografia Política, além do "olhar para a política nacional", que podia ser identificada pela amplitude de conhecimentos que ela abarca.

A Geografia Política é o campo de reflexões que te permite incorporar todos os conhecimentos particulares da Geografia e dá um sentido, um sentido de futuro para a Geografia. [...] a Geografia Política, por obrigatoriamente trabalhar com o movimento, com 0 conflito, com as tensões, as flexões, os acordos, de ver o território em movimento, como produto de ação política, e não econômico propriamente dito, dá um colorido novo. Então, o território ganha sentido. Por que o território o que é? É o espaço politicamente dominado. (COSTA, 2010, p. 30)

\footnotetext{
${ }^{14}$ No relato de Costa a Silva (2010), ele e Tonico (como chamavam Antonio Carlos Robert Moraes) tinham um projeto de mais publicações em conjunto, além do livro: Geografia crítica - a valorização do espaço, de 1993. Tal projeto não se efetivou, mas cada um a seu modo continuou na vertente teórica assumida a partir da renovação. Costa desenvolveu estudos e pesquisas no âmbito da Geografia Política, nela encontrando um campo fecundo de reflexões acerca do território, do espaço e da fronteira. Moraes, apesar da mesma formação, desenvolveu estudos e pesquisas acerca da história do pensamento geográfico, de teoria e método em Geografia, de história da Geografia e de Geografia histórica. Nessas frentes de atuação constata-se a presença acentuada do conceito de território.

Estudos Geográficos, Rio Claro, 17: 4-26, jan./jun. $2019 \quad$ (ISSN 1678-698X) http://www.periodicos.rc.biblioteca.unesp.br/index.php/estgeo
} 
Assim Costa justificava e conferia sentido à sua predileção pelo território em relação ao espaço, ao assumir uma posição perante e no interior do Movimento de Renovação. Além de conferir um lugar de relevância à Geografia Política, no Brasil.

A trajetória de Moraes e sua preferência pelos estudos acerca do território, num dado momento, se deram numa tensão com o conceito de espaço, tornado objeto da ciência geográfica no âmbito da renovação. Inicialmente, ele pretendia desvelar uma ontologia do espaço, mas havia declinado desse projeto e expor sua posição.

Em minha opinião [...] o espaço não é objeto de nada. Ciência Social estuda a sociedade nas suas várias relações e a Geografia estuda a relação da sociedade com o espaço. Ou seja, é a relação que é o objeto, não o espaço. Penso que este seja um tema central, o cerne da questão. [...] uma série de pessoas mantém a ideia do objeto como espaço e vão trabalhá-lo como se fosse sinônimo de superfície da Terra, voltando, portanto, a uma visão muito próxima, no meu entender, da visão tradicional do objeto. (MORAES, 2000, p. 148).

Um dos textos que marca essa "ruptura" é Historicidade, consciência e construção do espaço ${ }^{15}$. Em depoimento a Scarim (2000), Moraes relatou como foi o deslocamento teórico em sua trajetória intelectual no decorrer da renovação da Geografia, isto é, porque inicialmente se ocupou com as categorias trabalho e relações de produção, numa abordagem muito mais economicista do marxismo e da geografia econômica, e a percepção de que a análise deveria ser política. Essa percepção o fez deslocar-se e se dedicar aos estudos sobre política e cultura. O livro Ideologias geográficas é emblemático desse deslocamento: "[...] salvo um pouco de megalomania ou de egocentrismo meu, talvez seja o primeiro a colocar com clareza essa demarcação: a questão da representação, a questão da consciência", Moraes declarou a Scarim (2000, p.148). O argumento que deu origem ao livro era o de que "se podia discutir cultura a partir do marxismo (Gramsci e Lukács) e não na fenomenologia", justificou Moraes. Além daquele texto e do livro, a tese de doutorado de Moraes, fundamentada na História, seguia na direção de formular uma teoria do Brasil que fosse "geográfica". Esse direcionamento implicava em priorizar a dimensão política e o território, numa abordagem próxima de um marxismo historicista que possibilitava por em contato território e história e refundar a geografia humana como uma "história territorial".

No final da década de 1980, o Movimento de Renovação já acumulava críticas e autocríticas sobre seu curso e seus desdobramentos. Silva (2010) destaca o deslocamento operado por um dos expressivos protagonistas da renovação: Milton Santos, quanto aos conceitos de espaço e território. O argumento de Silva (2010) é o de que Milton Santos foi, paulatinamente, enfatizando cada vez mais o território, em relação ao espaço, ao longo de sua produção, a partir da década de $1990^{16}$. Tal deslocamento se devia à preocupação premente de pensar o Brasil em relação com a sociedade e o território. Em outros termos, alimentava essa preocupação as ideias de que o território "faz falar a nação" e a de que faltava uma teoria geográfica do Brasil. O texto: O retorno do território, publicado em 1994, põe em destaque o

\footnotetext{
${ }^{15}$ Esse texto apresentado no Encontro da UGI, no Rio de Janeiro, em 1982, foi "a espinha dorsal" do livro: Ideologias geográficas.

${ }^{16}$ Em depoimento a Silva (2010, p. 104), Arroyo discordou desse argumento ao afirmar que o território sempre esteve presente na obra de Milton Santos: "embora seu conceito central seja o espaço geográfico, ele nunca deixou de contemplar a escala nacional [...] nas suas análises, nas suas críticas nunca deixou de configurar a escala nacional”.

Estudos Geográficos, Rio Claro, 17: 4-26, jan./jun. $2019 \quad$ (ISSN 1678-698X) http://www.periodicos.rc.biblioteca.unesp.br/index.php/estgeo
} 
território como categoria de análise, mas, sobretudo, como materialidade e condição de existência da sociedade, e por isso se impunha a necessidade de revisão histórica constante. Citado inúmeras vezes, esse texto se tornou emblemático do evento O novo mapa do mundo, realizado em 1992, na Universidade de São Paulo. Em depoimento a Silva (2010, p. 102) Arroyo argumenta sobre a importância desse evento e o que ele significou naquele contexto.

[...] O novo mapa do mundo foi importante porque [...] teve um contexto do Brasil, na América Latina, no qual o discurso único começava a registrar aquele discurso neoliberal de que temos que pertencer ao "primeiro mundo", de que a globalização veio para que todos possam, agora sim, entrar no "primeiro mundo", então aquele discurso estava sendo gestado e estava sendo aplaudido pelos estados políticos, jornalísticos, e nos outros países, no Brasil também. [...]. Então o professor Milton [Santos] junto com outros intelectuais aqui estava fazendo a crítica, mas provavelmente sem serem ouvidos, inclusive dentro da universidade. Então por que foi importante $O$ novo mapa do mundo? Porque ele foi um evento que conseguiu trazer as discussões, as transformações efetivas que estavam experimentando no mundo, mas de uma forma crítica [...].

Esse evento, juntamente com o texto, expressam uma intervenção intelectual e política num contexto global e nacional em que se impunham o debate e - questionamento, e a contraposição ao pensamento único e à reificação da Globalização. Mas não só, segundo Arroyo, em depoimento a Silva (2010, p. 104), Santos estava dizendo que: "'na Geografia temos um precioso conceito que ajuda a discutir essa conjuntura, ajuda a contestar essa conjuntura que estamos vivendo'. [...]. É um conceito que ele recupera para chamar a atenção à Geografia, primeiro, e ao resto das Ciências Sociais [...]". Nesse sentido, o território estava destinado a desempenhar uma relevância epistemológica e política no projeto de renovação da Geografia. Mas cabe indagar sobre os vínculos entre classe social e sujeitos com o território e o espaço, a partir do Movimento de Renovação.

\section{POLIFONIA DO TERRITÓRIO E POLISSEMIA DE SUJEITOS}

Em meio às "vozes" dissonantes sobre o território e o espaço, a questão do sujeito foi paulatinamente se interpondo na reflexão geográfica, desde o Movimento de Renovação, nas décadas finais do século $X X$, até os dias atuais. A transformação social e a justiça social deram a tônica do discurso da renovação e passavam, necessariamente, pelo espaço e o território como também pela elucidação dos sujeitos. Quais as formas discursivas de que se reveste o sujeito ou os sujeitos? As referências à sociedade, à população, ao cidadão, às classes sociais, ao proletariado, ao camponês, aos movimentos sociais, aos povos (ribeirinhos, da floresta, cerradeiros, etc.), ora de forma genérica, ora de forma específica foram se plasmando aos conceitos de espaço e território. Os desafios em precisar e nomear "os sujeitos" não encontrou, até o momento, soluções consensuais. Os esforços no sentido de precisar a dimensão espacial e territorial dos sujeitos também se impuseram na ordem das reflexões, sob a forma de desafios teóricos e práticos.

Nas publicações das décadas de 1980-1990 encontram-se, esparsas ou de forma sistemática, reflexões no sentido de responder àquelas questões. Desse período, destaco inicialmente o livro: $O$ movimento operário e a questão cidade-

Estudos Geográficos, Rio Claro, 17: 4-26, jan./jun. $2019 \quad$ (ISSN 1678-698X) http://www.periodicos.rc.biblioteca.unesp.br/index.php/estgeo 
campo no Brasil, de Ruy Moreira, publicado em $1985^{17}$. Nesse livro encontram-se "o tema propriamente da geografia operária brasileira e o esboço de uma teoria da geografia operária", adverte Moreira $(2013$, p.8) no Prefácio à segunda edição. Nele se delineia a dialética entre o espaço e as classes sociais, tal como destaca Moreira (2013, p. 192):

A fábrica tem uma territorialidade necessariamente localizada, ao passo que o mercado, necessariamente, supralocal. Por isso, harmonizar relações de classes harmonizando relações de movimento de valor implica uma pactuação espacial de difícil encomenda em uma estrutura de formação social de interesses classistas geralmente tão díspares. Sujeitos gestores dessas esferas, as classes sociais seguem suas respectivas tendências de territorialidade. Fato que se reflete no Estado, que, não podendo se deslocar da territorialidade do antagonismo dessas classes, também não pode distanciar-se dela. Em uma relação à contramão do capital, que ora se localiza no espaço da fábrica, ora no espaço do mercado - estabelecendo com as esferas um caráter oportunista de espacialidade -, as classes sociais da formação geralmente buscam amalgamar-se nelas. (MOREIRA, 2013, p. 192-193).

No Discurso do avesso, publicado em 1987, Moreira revisa "criticamente" a história da Geografia para nela demonstrar como o pensamento geográfico vinha disseminando: um discurso genérico e abstrato e fragmentado sobre o homem, 0 "homem atópico", e a ideologia e a política dos estudos de população no ensino de Geografia. Uma vez revisada essa história e reconstituída as fontes teóricas dessa "geografia da população", seguia-se a proposta de uma "transposição do materialismo dialético-histórico à Geografia" (MOREIRA, 1987, p. 77).

$\mathrm{Na}$ década de 1980, Milton Santos (1996, p. 82) questionava ao mesmo tempo em que afirmava a dimensão espacial: "Será possível interpretar as classes sociais, defini-las, sem considerar a base territorial? [...] o valor do homem, assim como o do Capital em todas as suas formas, depende de sua localização no espaço". Nesse livre, $O$ espaço do cidadão, Milton Santos passa em exame os conceitos de homem, indivíduo, consumidor, classe e cidadão. Os conceitos não se excluem, pelo contrário, são dimensionados em relação ao espaço ou ao território.

É impossível imaginar uma cidadania concreta que prescinda do componente territorial. Vimos, já, que o valor do indivíduo depende do lugar em que está e que, desse modo, a igualdade dos cidadãos supõe, para todos, uma acessibilidade semelhante aos bens e serviços, sem os quais a vida não será vivida com aquele mínimo de dignidade que se impõe. Isso significa, em outras palavras, um arranjo territorial desses bens e serviços de que, conforme a sua hierarquia, os lugares sejam pontos de apoio, levando em conta a densidade demográfica e econômica da área e a sua fluidez. Num território onde a localização dos serviços essenciais é deixada à mercê da lei do mercado, tudo colabora para que as desigualdades sociais aumentem. (SANTOS, 1996, p. 116)

\footnotetext{
${ }^{17}$ A edição de 1985 foi publicada pela editora Vozes, em seu formato original. Uma edição reformulada pelo autor foi publicada, em 2013, pela editora Consequência.

Estudos Geográficos, Rio Claro, 17: 4-26, jan./jun. $2019 \quad$ (ISSN 1678-698X) http://www.periodicos.rc.biblioteca.unesp.br/index.php/estgeo
} 
Por sua temática, esse livro é emblemático da situação vivida no Brasil, depois de mais de duas décadas de regime militar, quando o processo de redemocratização e a constituinte estavam na pauta das discussões políticas. As proposições apresentadas nesse livro continuam atuais, em pleno século $\mathrm{XXI}$, e um exame minucioso delas merece ser feito, mas ultrapassa nosso objetivo no momento. Importa destacar o componente espacial e territorial das classes sociais, do cidadão e da cidadania sem que, necessariamente, se excluíssem mutuamente, enquanto figuras do sujeito. Talvez ele próprio tenha dado a melhor explicação sobre as escolhas que fez.

A questão do espaço tem a ver, nos anos [19] 70, com a minha relação com o mundo anglo-saxão, onde o espaço ganha uma força grande no vocabulário da disciplina. Daí eu o ter usado muito. Chegando ao Brasil, onde acontece a geografia que fiz mesmo, vejo que ela quer ser uma geografia cidadã: quero ser um scholar e também um cidadão. Essa geografia cidadã me apontou para a forma de a gente se inserir no debate social. (SANTOS, 2004, p. 34, grifos nossos)

Nos anos finais da década de 1980, no livro: Ideologias geográficas, publicado, em 1988, Moraes examina "A questão do sujeito na produção do espaço". Sua abordagem crítica chama a atenção para aspectos que considerava impregnados de uma concepção economicista e determinista do espaço, presentes tanto na geografia teorética, quanto na geografia crítica, ao desconsiderarem a dimensão da cultura, da política e da subjetividade nos modos pelos quais os sujeitos se relacionam com o espaço.

As formas espaciais são o produto de intervenções teleológicas, materializações de projetos elaborados por sujeitos históricos e sociais. Por trás dos padrões espaciais, das formas criadas, dos usos do solo, das repartições e distribuições, dos arranjos locacionais, estão concepções, valores, interesses, mentalidades, visões de mundo. Enfim, todo o complexo universo da cultura, da política e das ideologias. (MORAES, 1996, p. 16)

Essas formulações demandavam também que se considerasse a dimensão da consciência social forjada no "âmbito das relações sociais". Além dessas advertências, as formulações de Moraes se encaminham também na direção de uma "leitura" propositiva para o Brasil, nas décadas seguintes, tal como se pode constatar nos livros: Território e história no Brasil, publicado em 2002, nos anos iniciais desse século, e Geografia histórica do Brasil, publicado em $2009^{18}$. Há nessas obras, por seus temas e abordagem, os sinais do projeto intelectual de Moraes e sua preocupação com coerência de suas escolhas.

Da década de 1990 até as duas primeiras décadas desse século, o Movimento de Renovação foi perdendo o élan inicial. A temática territorial foi assumindo outras configurações, provocadas em grande parte pelas mudanças operadas no "socialismo real" e nas críticas ao marxismo, pelo advento da globalização e a emergência, no cenário mundial e nacional, de novos sujeitos

\footnotetext{
${ }^{18}$ Para Moraes (2009, p. 134): "Uma visão estratégica do território e das tendências da conformação territorial aparece como imperativa para a formulação de um projeto nacional na conjuntura incerta da atualidade mundial”. Nesse sentido, ele propôs a "elaboração de diretrizes geográficas para pensar o Brasil".

Estudos Geográficos, Rio Claro, 17: 4-26, jan./jun. $2019 \quad$ (ISSN 1678-698X) http://www.periodicos.rc.biblioteca.unesp.br/index.php/estgeo
} 
sociais, para os quais o emprego das categorias de análise marxistas parecia não dar conta da complexidade com que se manifestaram "os novos sujeitos". A busca pelo entendimento desses "sujeitos novos" 19 punha em questão o alcance explicativo das noções de classe social e consciência de classe ${ }^{20}$. Embora 0 pensamento sociológico tenha avançado em compreendê-los, essa não foi uma prerrogativa de tal pensamento. No pensamento geográfico contemporâneo há que se destacar, pelos menos, três geógrafos que, por perspectivas distintas, deslocaram, sem abandonar, o foco da concepção de classe social em direção a outras nuances dos sujeitos sociais.

Nessa perspectiva é fundamental destacar a trajetória de Carlos Walter Porto Gonçalves, no sentido de compreender como se depara e acolhe a temática ambiental e os movimentos sociais. Em depoimento a Scarim (2000), ele descreveu sua trajetória e o sentido que a questão ambiental assumiu na sua reflexão e na militância junto aos movimentos sociais. São expressivos de sua trajetória livros que marcaram os debates acerca dessa temática, à época: Paixão da terra, publicado em 1984, e Os (Des) caminhos do meio ambiente, publicado em 1989. Mobilizando teorias e conceitos oriundos da ecologia, da filosofia e de marxistas, em nada ortodoxos, como Thompson, Gonçalves punha em questão a relação homem-meio, sociedade-natureza, tanto no socialismo quanto no capitalismo. Como se houvesse encontrado sua "comunidade de destino", Gonçalves (1999, p.69) explicita uma concepção de movimento social.

A expressão movimento social ganha, assim, para a nossa compreensão das identidades coletivas um sentido geográfico muito preciso: é que o vemos como aquele processo através do qual um determinado segmento social recusa o lugar que, numa determinada circunstância espaço-temporal, outros segmentos sociais melhor situados no espaço social pelos capitais (Bourdieu) que já dispõem tentam lhe impor e, rompendo a inércia relativa em que se encontravam, se mobilizam movimentando-se em busca de afirmação das qualidades que acreditam justificarem sua existência. (GONÇALVES, 1999, p. 69).

A produção de Gonçalves e sua atuação intelectual e política demandam uma interpretação que ultrapassa nossos objetivos no momento. Em seus trabalhos no início desse século, veja-se, por exemplo, o artigo: De saberes e de territórios: diversidade e emancipação a partir da experiência latino-americana, de 2006, identificam-se o mesmo pensamento avesso aos preconceitos e a abertura ao diálogo com o pensamento decolonial, o foco nos movimentos sociais latino-

\footnotetext{
${ }^{19}$ Essa denominação "sujeito novo" me veio pel0 livro: Quando novos personagens entraram em cena de Eder Sader, publicado em 1988. A profundidade da pesquisa que deu origem ao livro e a contribuição de Sader, me parece ter sido muito bem formulada por Chauí (p.10), no prefácio à segunda edição. À questão "Por que sujeito novo?", ela explicou: "Antes de mais nada, porque criado pelos próprios movimentos sociais populares do período: sua prática os põe como sujeitos sem que teoria prévias os houvessem constituído ou designado. Em segundo lugar, porque se trata de um sujeito coletivo e descentralizado, portanto, despojado das duas marcas que caracterizaram o advento da concepção burguesa da subjetividade: a individualidade solipsista ou monádica como centro de onde partem ações livres e responsáveis e o sujeito como consciência individual soberana de onde irradiam ideias e representações, postas como objetos domináveis pelo intelecto. O novo sujeito é social; são os movimentos sociais populares em cujo interior indivíduos, até então dispersos e privatizados, passam a definir-se, a reconhecer-se mutuamente, a decidir e agir em conjunto e a redefinir-se a cada efeito resultante das decisões e atividades realizadas. Em terceiro lugar, porque é um sujeito que, embora coletivo, não se apresenta como portador da universalidade definida a partir de uma organização determinada que operaria como centro, vetor e telos das ações sócio políticas e para a qual não haveria propriamente sujeitos, mas objetos ou engrenagens da máquina organizadora”.

${ }^{20}$ Para essa discussão ver o interessante livro: A corrosão do caráter, de Richard Sennet.

Estudos Geográficos, Rio Claro, 17: 4-26, jan./jun. 2019 (ISSN 1678-698X) http://www.periodicos.rc.biblioteca.unesp.br/index.php/estgeo
} 
americanos, a valorização da dimensão territorial desses movimentos, a crítica rigorosa ao capitalismo e a sua ideologia.

Destaco outra via de estudos e abordagens sobre a temática territorial que, sem desconsiderar o legado do Movimento de Renovação, têm avançado na compreensão dos sujeitos no âmbito do pensamento geográfico brasileiro contemporâneo. Refiro-me aos estudos de Haesbaert (1997, 2002, 2007), nos quais se encontram temáticas como: identidade regional e territorial, processos de territorialização, desterritorialização e reterritorialização e a retomada de conceitos clássicos como o de região, deixado um tanto à margem nos estudos da geografia renovada. Haesbaert tem sido um dos geógrafos brasileiros cujos trabalhos muito têm contribuído para a reflexão teórica e conceitual sobre de território. Assim ele descreveu seu interesse por esses temas: "A 'região' surgiu pra mim meio como o 'pays' de Vidal de La Blache. Cada vale da Serra era para mim uma grande descoberta. [...] Novas paisagens me marcavam muito" (HAESBAERT, 1998, p. 97).

A curiosidade e o fascínio infantil resultaram em motivações para estudos e pesquisas: "A verdade é que duas grandes linhas atravessaram este percurso acadêmico: em nível teórico os conceitos de região e regionalização, nas múltiplas conexões local/regional/global e, em nível empírico, aquilo que eu poderia denominar a saga dos gaúchos" (HAESBAERT, 1998, p. 98). A atualidade dessa temática foi mais bem desenvolvida em sua tese de doutoramento, que dá origem ao livro: "Des-territorialização e identidade: a rede "gaúcha" no nordeste", Haesbaert (1997). Nele, a revisão teórica e conceitual acerca do território evidencia a potência desse conceito na compreensão do mundo atual.

Essa distinção entre território como instrumento do poder político (quase sempre de caráter estatal, ligado à questão da cidadania) e território como espaço de identidade cultural, instrumento de um grupo cultural e/ou religioso, é fundamental no mundo contemporâneo, dentro do debate entre universalistas (defensores de uma "cidadania-mundo", calcada ou não na territorialidade-padrão dos Estados-nações) e multiculturalistas (defensores do respeito às especificidades culturais, que pode incluir as diferentes concepções de territorialidade moldadas no interior de cada cultura). (HAESBAERT, 1997, p. 37).

Tendo por referências autores de outras filiações teóricas, Haesbaert (2002) tem nos possibilitado avançar na compreensão dos estreitos vínculos entre território e cultura, território e identidade, para além das discussões canonizadas sobre território e poder.

[...] o território é o produto de uma relação desigual de forças, envolvendo o domínio ou o controle político-econômico do espaço e sua apropriação simbólica, ora conjugados e mutuamente reforçados, ora desconectados e contraditoriamente articulados. Esta relação varia muito, [...], conforme as classes sociais, os grupos culturais $e$ as escolas geográficas [...]. Como no mundo contemporâneo vive-se concomitantemente uma multiplicidade de escalas, numa simultaneidade atroz de eventos, vivenciam-se também, ao mesmo tempo, múltiplos territórios. Ora somos requisitados a nos posicionar perante uma determinada territorialidade, ora perante outra, como se nossos marcos de referência e controle espaciais fossem perpassados por múltiplas

Estudos Geográficos, Rio Claro, 17: 4-26, jan./jun. $2019 \quad$ (ISSN 1678-698X) http://www.periodicos.rc.biblioteca.unesp.br/index.php/estgeo 
escalas de poder e de identidade. Isto resulta em uma geografia complexa, uma realidade multiterritorial (ou mesmo transterritorial) que se busca traduzir em novas concepções [...]. (HAESBAERT, 2002, p. 121).

Com efeito, não menos relevantes são as contribuições Bernardo Mançano Fernandes, sobretudo, quanto à relação entre território, espaço e movimentos sociais. As motivações que o conduziram a se interessar pela geografia, particularmente a geografia agrária, e, posteriormente, a desenvolver pesquisas sobre movimentos sociais e território, foram relatadas numa entrevista, no final da década de 1990.

Eu comecei a trabalhar com a questão dos sem-terra em 1984, quando ainda estava na Pastoral da Juventude. Era um trabalho de apoio, a partir das comunidades urbanas. Meu envolvimento mais científico e político começou em 1986. Eu participava das reuniões, desde as de base até as reuniões das coordenações. [...]. Com livre trânsito por dentro da forma de organização do MST, eu fui assumindo compromissos, trabalhando com a formação de professores, dando aulas nas escolas do MST. (FERNANDES, 1998, p. 126-127)

A militância, inicialmente junto à Igreja, não tardou a se desdobrar numa atuação política e intelectual. Traço característico de gerações que herdaram - legado do Movimento de Renovação. O interesse pela questão agrária e 0 Movimento dos Trabalhadores rurais Sem Terra (MST) estão na origem do que tem sido a contribuição de Fernandes para o pensamento geográfico brasileiro contemporâneo. Ao avaliar o alcance de suas contribuições, na elucidação da temática territorial em relação aos movimentos sociais, Fernandes afirmou, em relato a Silva (2010, p. 50-51):

Minha contribuição para a construção desses conceitos, para a discussão do conceito de território, está na compreensão do processo de territorialização e desterritorialização; na tentativa da construção de uma Geografia dos movimentos camponeses como movimentos socioterritoriais. [...]. (FERNANDES, 2008, p. 50-51)

$\mathrm{Na}$ avaliação crítica acerca dos interesses pelo território, Fernandes ressalta que a temática territorial em relação aos movimentos sociais foi mais bem desenvolvida na Sociologia do que na Geografia. Somente na década de 1980, a Geografia teria despertado e buscado compreender aquela relação. Esse reconhecimento da temática justifica, em parte, a profusão de estudos numa perspectiva sociológica, dos quais os geógrafos passaram a se referenciar quando o assunto é movimentos sociais. Apesar do avanço desses estudos, Fernandes lamenta a ausência de uma abordagem geográfica e questiona o uso ideológico do conceito território nas políticas públicas e territoriais, e seu vínculo com 0 pensamento liberal e a globalização. Em sua avaliação, o território tornou-se um poderoso conceito na atualidade.

Qual a razão que levou o território a ser conceito central hoje nas políticas de desenvolvimento. Por que é que o território ganhou esse status? E aí eu vejo duas explicações para isso. De um lado, o uso

Estudos Geográficos, Rio Claro, 17: 4-26, jan./jun. 2019 (ISSN 1678-698X) http://www.periodicos.rc.biblioteca.unesp.br/index.php/estgeo 
banal do conceito principalmente pelas agências multilaterais e pelos governos. Poderíamos chamar de região, poderíamos chamar de espaço, mas chamam de "território". E o uso do conceito de território pelos movimentos camponeses mais no sentido próprio do território, que é o sentido da soberania. Então, o uso do conceito de território pelas instituições governamentais e multilaterais não está muito vinculado à ideia de soberania, mas está muito mais vinculado à ideia de área econômica para expansão das políticas neoliberais. Então, o território para eles é sinônimo de "espaço geográfico", somente, ou seja, é uma área, uma superfície, um espaço onde eu vou executar uma política para desenvolver o capitalismo. (FERNANDES, 2010, p. 50-51, grifos nossos).

Mas há outros sentidos para o conceito de território, que baliza um contra discurso, porque os sujeitos que o professam percebem o território a partir de suas condições de existência, de suas lutas e de sua autonomia. O território é condição de possibilidade de existirem como sujeitos sociais.

[...] para os movimentos populares, os movimentos camponeses, o conceito de território está vinculado à ideia de vida, de propriedade para todos, está vinculado à ideia de nação, à ideia de autonomia, de hegemonia e resistência, de soberania, de poder. [...]. Então, essas são duas características do uso do território hoje nesse mundo globalizado. O território utilizado como uma expressão banal, onde serviria qualquer outro, e o território como uma expressão crítica, ou seja, é a questão da conquista, é a questão de se manter, de existir, é a questão de defender o território. (FERNANDES, 2010, p. 51)

Essas duas características expressam as formas de "uso" do território e evidenciam as contradições no âmbito da "questão agrária", pois, argumenta Fernandes (1999, p. 224): "em seu conteúdo, a questão agrária é, antes de tudo, a questão da terra, da democratização da propriedade da terra", no Brasil. Ora, a democratização da propriedade da terra "é a solução do problema fundiário e o estabelecimento de um projeto socioeconômico e político camponês, o ponto de partida para a transformação da questão agrária" (FERNANDES, 1999, p.225). Essa avaliação crítica de Fernandes não está desvinculada de um comprometimento político mais amplo, que consiste em recuperar a dimensão transformadora do campesinato. Uma classe social relegada a segundo plano, se comparada ao proletariado. O desafio é o de elucidar os modos de ser desse sujeito social, o campesinato, que aparece simultaneamente como classe e como movimento social. Segundo Fernandes (1999, p.225):

[...] as ocupações acontecem nos processos de espacialização e territorialização do MST. A espacialização é um processo ininterrupto e tem como princípio a constituição do espaço de socialização política, que, dimensionado, possibilita a construção do espaço de luta e resistência [...]. Acampados na terra que não cumpre a sua função social, resistem pelo enfrentamento contra os latifundiários e - Estado. [...]. Espacializam-se pelas estradas e avenidas, do campo à cidade, em caminhadas, marchas, ocupando prédios públicos e espaços políticos. Esses sujeitos formam-se em um movimento sócio-espacial e, com suas práticas, procuram superar as interpretações da realidade que os excluem. Desse modo, garantem

Estudos Geográficos, Rio Claro, 17: 4-26, jan./jun. 2019 (ISSN 1678-698X) http://www.periodicos.rc.biblioteca.unesp.br/index.php/estgeo 
a terra como fração do território e espaço político para reproduzirem os processos de espacialização e territorialização. E, desse modo, tecem uma rede de luta e resistência em quase todo o país, organizados estrategicamente em todas as regiões e nos principais Estados, constituindo-se em movimento socioterritorial.

Os desafios teóricos contemporâneos postos ao pensamento geográfico, quanto à relação entre território, classes sociais e sujeitos, são tributários do legado do Movimento de Renovação, em grande parte. Todavia, nem todos os desafios têm sua origem ou encontram solução na herança da renovação. A emergência de movimentos sociais e de sujeitos sociais (coletivos), num dado momento da história recente, evidencia o que se afirma. Parece-nos que um dos desafios consiste em usar o mesmo repertório metodológico e categorial do marxismo para conciliar classes sociais e movimentos sociais e/ou sujeitos sociais. Cabe indagar sobre que os aproximam e o que os distanciam. Temos alguns traços, algumas indicações de que os novos sujeitos não se apresentam como portadores de uma universalidade definida, o que nos parece ter sido imputada às classes sociais, sobretudo, ao proletariado como classe revolucionária. Ao que parece também, os novos sujeitos não têm uma organização determinada ou definida, uma consciência e ação imputadas ou por um telos inscrito desde sua origem, como se pode encontrar em algumas interpretações das classes sociais na história.

\section{CONSIDERAÇÕES FINAIS}

Essas reflexões foram premidas por Kairos, "momento de decisão, ocasião crítica, conjuntura na qual é importante que alguma coisa seja feita ou dita", tal como assegura Castoriadis (1987, p. 12). Sendo assim, trazem as marcas de um pensamento ainda preso no fluxo das ideias que demanda mais tempo para sua maturação. Todavia, do percurso feito, é preciso explicitar algumas escolhas e exclusões. Nosso percurso, dentre outros possíveis, se ateve ao tema proposto e procurou situá-lo no pensamento geográfico brasileiro contemporâneo. Daí a ausência de referências desse debate em outros cenários.

Priorizamos o Movimento de Renovação da Geografia, no Brasil, por entender que a introdução do marxismo no pensamento geográfico brasileiro, como um dos fundamentos mais expressivos da geografia crítica ou renovada, constitui um campo fecundo de discussão a balizar as relações entre território, classes sociais e sujeitos. Ao longo desse percurso identificam-se protagonistas e tentativas de conciliação entre a abordagem marxista das classes sociais com os novos sujeitos e os movimentos sociais.

As reflexões sobre sujeito, existência e lugar, numa abordagem fenomenológica, no âmbito da geografia humanista foram, propositadamente, destinadas a outras reflexões, porque ultrapassam nossos objetivos no momento. É sabido que o Movimento de Renovação da Geografia, no Brasil, não se constituiu apenas de uma ramificação: a geografia crítica ou geografia nova. Todavia, abordar o tema proposto, numa abordagem da Geografia Humanista Cultural demandaria revisar as influências filosóficas recebidas, identificar e mapear seus protagonistas, com suas respectivas contribuições, além de demandar uma revisão dos conceitos de sujeito e lugar numa amplitude inestimável para a ocasião. Há uma vasta produção teórica a subsidiar tais reflexões.

Estudos Geográficos, Rio Claro, 17: 4-26, jan./jun. 2019 (ISSN 1678-698X) http://www.periodicos.rc.biblioteca.unesp.br/index.php/estgeo 
Ademais, as pesquisas sobre o pensamento geográfico brasileiro contemporâneo têm pautado nossas investigações e sua fecundidade não deixa de proporcionar novas descobertas. Dos desafios teóricos contemporâneos identificados importa registrar que: nem todas as pautas do Movimento de Renovação encerraram a discussão sobre a renovação epistemológica da Geografia; há uma polissemia em torno do território e do espaço, nem sempre convergentes; há uma polifonia de sujeitos não, necessariamente, compreensíveis pelas chaves de interpretação do "marxismo". E uma questão fundamental se impõe e persiste: o que, nessa diversidade de modos de ser, pensar, fazer e dizer mantém uma sociedade coesa?

\section{REFERÊNCIAS}

ARANTES, P. E. Entrevista. In: NOBRE, M.; REGO, J. M. (Orgs.). Conversas com filósofos brasileiros. São Paulo: Editora 34, 2000.

BLACHE, V. de La. Princípios de geografia humana. [1. ed. francesa 1921]. 2. ed. Portugal: Edições Cosmos, 1928.

CARVALHO, M. B. de. Da antropogeografia do final do século XIX aos desafios transdisciplinares do final do século $\mathbf{X X}$ : 0 debate sobre as abordagens integradas da natureza e da cultura nas ciências sociais. 350 f. Tese (Doutorado em Ciências Sociais) Universidade Católica de São Paulo, São Paulo, 1998.

CASTORIADIS, C. Alcance ontológico da história da ciência. As encruzilhadas do labirinto II: os domínios do homem. Rio de Janeiro: Paz e Terra, 1987.

CLAVAL, P. A revolução pós-funcionalista e as concepções atuais da geografia. In: MENDONÇA, F.; KOZEL, S. (Orgs.). Elementos de epistemologia da geografia contemporânea. Curitiba: UFPR, 2002. p. 11-43.

COSTA, W. M. da. Entrevista. In: SILVA, A.C. da. O pensamento geográfico brasileiro na travessia do século $X X$ para o $X X I$ : o território na trama das significações imaginárias. 578f. Tese (Doutorado em Geografia). Universidade Estadual "Júlio de Mesquita Filho", Presidente Prudente, 2010. 2 v. p. 5-33.

FERNANDES, B. M. Entrevista: A luta pela terra. GeoUERJ: Revista do Departamento de Geografia, UERJ. Rio de Janeiro, n. 3, p. 121-131, jun. 1998.

Entrevista. In: SILVA, A.C. da. O pensamento geográfico brasileiro na travessia do século XX para o XXI: o território na trama das significações imaginárias. 578f. Tese (Doutorado em Geografia). Universidade Estadual "Júlio de Mesquita Filho", Presidente Prudente, 2010.. 2 v. p. 34-49.

FREITAS, W. D. de. Geografia, militância e marxismo. A trajetória de Horieste Gomes e sua participação no Movimento de Renovação da Geografia Brasileira. 352f. Tese (Doutorado em Geografia). Universidade Federal de Goiás, Goiânia, 2014.

GEIGER, P. P. Entrevista: Memória e histórias sobre o IBGE. GeoUERJ: Revista do Estudos Geográficos, Rio Claro, 17: 4-26, jan./jun. $2019 \quad$ (ISSN 1678-698X) http://www.periodicos.rc.biblioteca.unesp.br/index.php/estgeo 
Departamento de Geografia, Rio de Janeiro, n. 10, p.113-127, º sem. 2001.

GONÇALVES, C. W. P. A geografia está em crise: viva a geografia. Boletim Paulista de Geografia, São Paulo, n. 55, p. 5-30, nov. 1978.

Paixão da Terra: ensaios críticos de ecologia e geografia. Rio de Janeiro: Rocco, 1984.

Os (Des) caminhos do meio ambiente. São Paulo: Contexto, 1989.

A territorialidade seringueira. Geografia e movimento social. GEOgraphia. Niterói, Ano 1, n.2, p. 67-88, 1999.

Geografia nos varadouros do mundo: da territorialidade seringalista (o seringal) à territorialidade seringueira (a Reserva Extrativista). Brasília: Ibama, 2003.

De saberes e de territórios: diversidade e emancipação a partir da experiência latino-americana. GEOgraphia. Niterói, Ano VIII, n.16, p.41-55, 2006.

. Entrevista. In: SCARIM, P. C. Coetâneos da crítica: contribuição ao estudo do movimento de renovação da geografia brasileira. 247 f. Dissertação (Mestrado em Geografia) Universidade de São Paulo, São Paulo, 2000. p. 63-101.

HAESBAERTH, R.. Des-territorialização e identidade: a rede "gaúcha" no nordeste. Niterói: EDUFF, 1997.

. Território e globalização. GeoUERJ: Revista do Departamento de Geografia, UERJ. Rio de Janeiro, n.5, p. 7-19, jan./jun. 1999.

Territórios alternativos. Niterói, RJ: EDUFF, 2002.

O mito da desterritorialização: do "fim dos territórios" à multiterritorialidade. Rio de Janeiro: Bertrand Brasil, 2004.

- Viver no limite: território e multi/transterritorialidade em tempos de insegurança e contenção. Rio de Janeiro: Bertrand Brasil, 2014.

LACOSTE, Y. A geografia - isso serve em primeiro lugar, para fazer a guerra. 2. ed. Campinas, SP: Papirus, 1989.

MORAES, A. C. R. Contribuição para uma história crítica do pensamento geográfico: Alexandre Von Humboldt, Karl Ritter e Friedrich Ratzel. Dissertação (Mestrado em Geografia). São Paulo: DG/FFLCH/USP, 1983.

1987.

Geografia: pequena história crítica. [1. ed.1981]. 7. ed. São Paulo: Hucitec,

Ideologias geográficas: espaço, cultura e política no Brasil. [1. ed.1988] 3. ed. São Paulo: Hucitec, 1996.

Estudos Geográficos, Rio Claro, 17: 4-26, jan./jun. $2019 \quad$ (ISSN 1678-698X) http://www.periodicos.rc.biblioteca.unesp.br/index.php/estgeo 
Entrevista. In: SCARIM, P. C. Coetâneos da crítica: contribuição ao estudo do movimento de renovação da geografia brasileira. 247 f. Dissertação (Mestrado em Geografia) Universidade de São Paulo, São Paulo, 2000. p. 102-126.

. Território e história no Brasil. São Paulo: Hucitec, 2002.

Geografia histórica do Brasil: cinco ensaios, uma proposta e uma crítica. São Paulo: Annablume, 2009.

MORAES, A. C. R., COSTA, W. M. da. Geografia crítica: a valorização do espaço. São Paulo: Hucitec, 1993.

MOREIRA, R. O que é geografia? [1. ed. 1980] 2. ed. São Paulo: Brasiliense, $1982 a$.

A geografia serve para desvendar máscaras sociais. In: MOREIRA, R. (Org.). Geografia: teoria e crítica. O saber posto em questão. Petropólis-RJ: Vozes, 1982b.

O discurso do avesso: para a crítica da geografia que se ensina. Rio de Janeiro: Dois Pontos, 1987.

O movimento operário e a questão cidade-campo no Brasil. Classes urbanas e rurais na formação da geografia operária brasileira. Rio de Janeiro: Consequência, 2013.

OLIVEIRA, A. U. de. Espaço e tempo: compreensão materialista e dialética. In: SANTOS, M. (Org.). Novos rumos da geografia brasileira. [1. ed. 1982]. 4. ed. São Paulo: Hucitec, 1996. p. 66-110.

Entrevista. In: SCARIM, Paulo César. Coetâneos da crítica: contribuição ao estudo do Movimento de Renovação da Geografia brasileira. 247 f. Dissertação (Mestrado em Geografia) Universidade de São Paulo, São Paulo, 2000. p. 5-44.

SADER, E. Quando novos personagens entraram em cena. Experiências e lutas dos trabalhadores da Grande São Paulo 1970-1980.

SANTOS, M. Por uma geografia nova. São Paulo: Hucitec, 1978.

Reformulando a sociedade e o espaço. Geografia e Sociedade: os novos rumos do pensamento geográfico. Revista de Cultura Vozes, Rio de Janeiro, v. LXXIV, ano 74, n. 4, p. 37-48, mai. 1980.

Espaço e método. São Paulo: Nobel, 1985.

. O espaço geográfico como categoria filosófica. Terra Livre, São Paulo, n. 5, p. 9-20, 1988.

SANTOS, Milton. Entrevista: Espaço, mundo globalizado, modernidade. In: Técnica, espaço, tempo: globalização e meio técnico-científico informacional. 2. ed. São Paulo: Hucitec, 1996a. p. 169-188.

Estudos Geográficos, Rio Claro, 17: 4-26, jan./jun. 2019 (ISSN 1678-698X) http://www.periodicos.rc.biblioteca.unesp.br/index.php/estgeo 
O espaço do cidadão. [1. ed. 1987]. 3. ed. São Paulo: Nobel, 1996b.

Alguns problemas atuais da contribuição marxista à geografia. In: SANTOS, M. (Org.). Novos rumos da geografia brasileira. São Paulo: Hucitec, 1996c. p. 131-149.

Testamento intelectual. São Paulo: UNESP, 2004.

SENNET, R. A corrosão do caráter. Rio de Janeiro-São Paulo: Record, 2009.

SILVA, A.C. da. $\mathbf{O}$ pensamento geográfico brasileiro na travessia do século $\mathbf{X X}$ para o XXI: o território na trama das significações imaginárias. 578f. Tese (Doutorado em Geografia). Universidade Estadual "Júlio de Mesquita Filho", Presidente Prudente, 2010.

O pensamento geográfico entre a sociologia do conhecimento e a ideologia. Revista Formação, n. 18, v.1, p. 03-23, jan./jun., 2011.

Território e significações imaginárias no pensamento geográfico brasileiro. Goiânia: Editora UFG, 2013.

O território no pensamento geográfico brasileiro contemporâneo. Boletim Goiano,v. 36, n.1, p. 27-47, jan./abr. 2016.

SILVA, A. C. da. A renovação geográfica no Brasil -1976/1983 (As Geografias Crítica e Radical e uma perspectiva teórica). Boletim Paulista de Geografia, São Paulo, n. 60, p. 73-140, 1984.

SOUZA, M. J. L. de. "Espaciologia": uma objeção (crítica aos prestigiamentos pesudo-críticos do espaço social). Revista Terra Livre, São Paulo, n. 5, p. 21-45, 1988.

VESENTINI, J. W. O que é crítica. Ou: qual é a crítica da geografia crítica? GEOUSP - Espaço e Tempo, São Paulo, n. 26, p.29-43, 2009. 